\title{
The mechanism of the bottom-crashing rockfall of a massive layered carbonate rock mass at Zengziyan, Chongqing, China
}

\author{
Kai He ${ }^{1}$, Yueping Yin ${ }^{2} *_{\odot}$, Bin Li ${ }^{1}$ and Chunli Chen ${ }^{2}$ \\ ${ }^{1}$ Key Laboratory of Neotectonic and Goehazard, Ministry of Land Resources, Institute of Geomechanics, Chinese \\ Academy of Geological Sciences, Beijing 100081, The People's Republic of China. \\ ${ }^{2}$ Technical Center for Geo-Hazards Prevention of MNR, China, China Institute for Geo-Environment Monitoring, \\ Beijing 100081, The People's Republic of China. \\ ${ }^{*}$ Corresponding author. e-mail: yyueping@mail.cgs.gov.cn
}

MS received 10 July 2018; revised 8 October 2018; accepted 2 December 2018; published online 6 April 2019

Multiple carbonate cliffs are distributed in the karst mountain areas of southwestern China. The dynamic process and failure mechanism of rockfalls in the cliffs are complicated and undefined, and can be dangerous for settlements. Moreover, it is difficult to identify the potential for such failures before they occur. The rockfall of the Zengziyan cliff at Chongqing, China, is used as an example for studying this type of failure and to determine the developmental characteristics of rockfall, expounding on the evolving process from a cliff to an unstable rock mass through to rockfall. A fracturing-crashing failure mode is proposed, based on the evolutionary characteristics of damage development, compression-induced fracturing, rock mass crashing and overall rockfall. Finite difference numerical simulations were used to analyse and validate the failure mode of the Zengziyan cliff under three simulation conditions. The results of the simulations indicated that strength deterioration at the bottom of the cliff was the root cause of its fracturing-crashing rockfall. The outcomes of this paper could provide a new analytical model and theoretical basis for identifying and analysing similar types of geological disasters in the mountainous areas of southwestern China, and may provide valuable reference information for further mechanical analysis, stability evaluation and engineering prevention of unstable rock masses prone to a fracturing-crashing rockfall.

Keywords. Bottom zone; failure mode; fracturing-crashing rockfall; damage-induced deterioration; numerical simulation.

\section{Introduction}

Subject to long-term tectonic movement and fluvial erosion, the karst mountain areas in southwestern China mostly exhibit a boot-shaped landform characterised by steep and thick upper limestone strata above a lower flat strata of shale or siltstone. Because of the structural plane and limited rock strength, these areas are extremely hazardous areas for rockslides, with many catastrophic rockslides occurring in the region. For example, the Jiguanling rock landslide in Wulong, China, occurred in 1994 when a steep dip and layered carbonate rock slope affected by underground mining exhibited a composite failure process and toppled to collapse. The total collapsed mass was $4,000,000 \mathrm{~m}^{3}$; 
36 people were injured or killed during the catastrophe and the $\mathrm{Wu}$ river was unnavigable for more than 90 days (Li et al. 2016). Another example is the Gongjiafang rock slope located on the left bank of the Yangzi river in Wushan, China, which slid into the river in 2008. Although this landslide did not have any casualties, it induced an impulse wave disaster. Research has shown that the highest wave caused by the Gongjiafang rockslide was more than $31 \mathrm{~m}$ high and threatened the safety of the county town of Wushan located $4.5 \mathrm{~km}$ upstream (Huang et al. 2012). In 2009, a huge catastrophic rockslide-rock avalanche (fragment flow) took place at the Jiweishan hill in Wulong, China, resulting in a long runout length of $1.25 \mathrm{~km}$ along Blacksmith valley. Over $7,000,000 \mathrm{~m}^{3}$ rock mass was disintegrated and covered an area of $0.47 \mathrm{~km}^{2}$. An iron-ore mine was obliterated, along with a loss of 74 people (Yin et al. 2011; Feng et al. 2016). The Jianchuandong tower-shaped unstable rock mass, located on the left bank of the Wuxia gorge in the three-gorges reservoir area, guards the golden waterway with a volume of approximately $360,000 \mathrm{~m}^{3}$. Fluctuations in the water level of the reservoir have been weakening the bottom of the Jianchuandong rock mass. Once the rock collapses, it will become a major safety hazard and will cause huge economic losses (Yin et al. 2015).

This problem is not limited to China. Large rockslide disasters are a serious threat to community security and development all over the world. Existing studies have shown that damage to the soft base and the differential deformation between hard and soft strata are important causes of the rockslide disasters that occur in layered sedimentary strata areas (Terzaghi 1950; Poisel et al. 1991, 2005; Hungr 1981; Hungr et al. 2001, 2014). The cutting of the joint fissures and their control of the shape of the unstable rock mass is also a reason for the high incidence of rockslides occurring in the karst mountainous area (Peisser et al. 2002; Susan et al. 2002; Frayssines and Hantz 2006). Disturbances caused by underground mining, karstification, differential weathering and other external dynamic effects can also induce failure in unstable rock masses (Jones et al. 1992; Hungr and Evans 2004; Glastonbury and Fell 2008).

Most previous studies have focused on the geological background, the structure of the rock mass and influencing factors when examining rockfalls. These studies have achieved significant progress in determining failure mechanisms, stability evaluation and preventive measures. However, theoretical research of rockfalls still lags behind research on other types of geological disasters such as slides and flows.

There are a variety of disaster-inducing types of rock masses widely distributed in the mountainous areas of southwestern China, particularly towershaped and slab-shaped unstable rock masses with large height-diameter ratios. Because of the shape characteristics and limited strength of such rock masses, fracturing-crashing rockfalls are more likely to occur and threaten the safety of residents and towns in these mountainous areas. Unlike the usual landslide types (Hungr et al. 2014), a new type of rockfall is introduced here. A fracturingcrashing rockfall is defined as the failure mode of a high and steep unstable rock mass at the cliff caused by the deterioration of mechanical properties in the bottom zone of the unstable rock mass. In this failure mode, the bottom zone is compressed to fracturing which induces rock crashing due to both the gravity load of the overlying rock mass and other external dynamic factors. This type of rockfall is difficult to identify early and its geological model is hard to generalise. Moreover, its dynamic process is complicated. The Zengziyan cliff in Nanchuan, Chongqing, China, serves as an example of this type of rockfall. In this work, we systematically investigate the fracturing-crashing mode of this rockfall using a geological survey, conducted analysis and validation through numerical simulation.

\section{Developmental characteristics and disaster evolution}

\subsection{The developmental characteristics of a cliff prone to a fracturing-crashing rockfall}

A large rockfall occurred in the Zengziyan Cliff in Nanchuan, Chongqing, China, on 12 August 2004. This failed rock mass with a height of $230-250 \mathrm{~m}$ and volume of approximately $560,000 \mathrm{~m}^{3}$ fell over the course of only $13 \mathrm{~s}$. Fortunately, there were no casualties due to a timely warning (figure 1). The failed rock mass of the Zengziyan cliff was tower shaped, bounded by two groups of nearly orthogonal steep dip joints. A Maokou formation of Permian strata $\left(\mathrm{P}_{2} m\right)$ was exposed on the Zengziyan Cliff with a dip direction of $280^{\circ}-300^{\circ}$ and a dip angle of $4^{\circ}-5^{\circ}$. The lithology of the Zengziyan Cliff is thick-bedded limestone. A subsequent investigation shows that the unloading fissures of the failed 
rock mass extended mostly from the top to the toe of the cliff prior to fall (figure 2b). This change suggests that the bottom zone of the failed rock mass had been in a compressive stress field with an area of stress concentration. Based on our investigation and other field surveys, the development characteristics of high, steep rock masses such as the Zengziyan cliff that are prone to fracturingcrashing rockfall can be summarised as follows:
(1) Generally speaking, such kind of rock mass is located in gently inclined or horizontal strata, mostly at the edge of boot-shaped slopes with an upper hard and a lower soft strata, as well as a steep upper cliff and a gentle lower slope.

(2) Joints and fissures are well developed. Steep dip joints and unloading fissures are especially common, and the controlling fissures generally
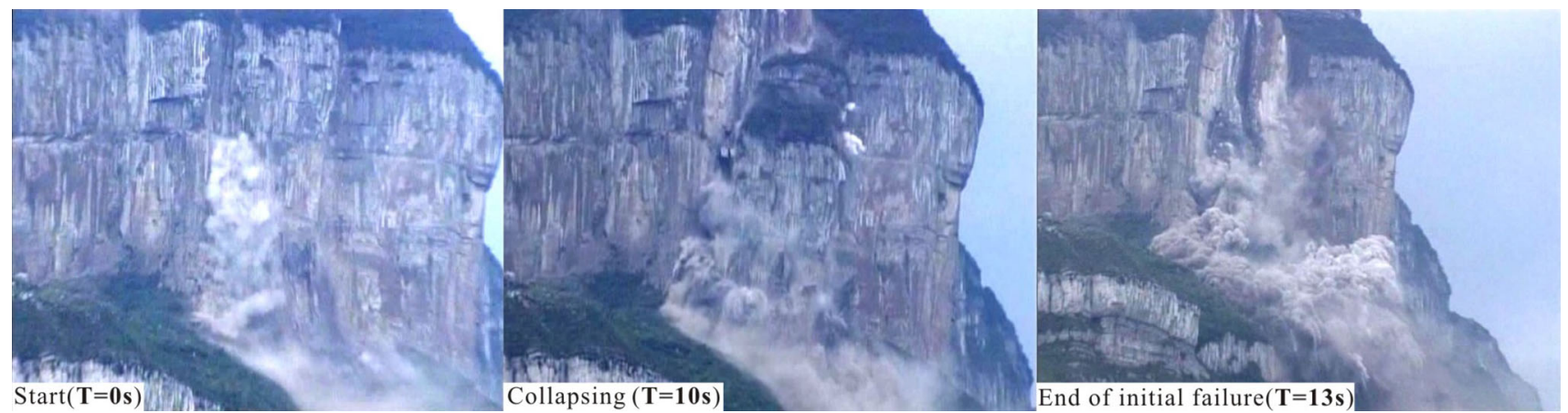

Figure 1. Initial failure process of the Zengziyan cliff in Nanchuan, Chongqing, China (based on He et al. (2018), figure 3). These images were taken from a video that captured the initial failure process of the rockfall.

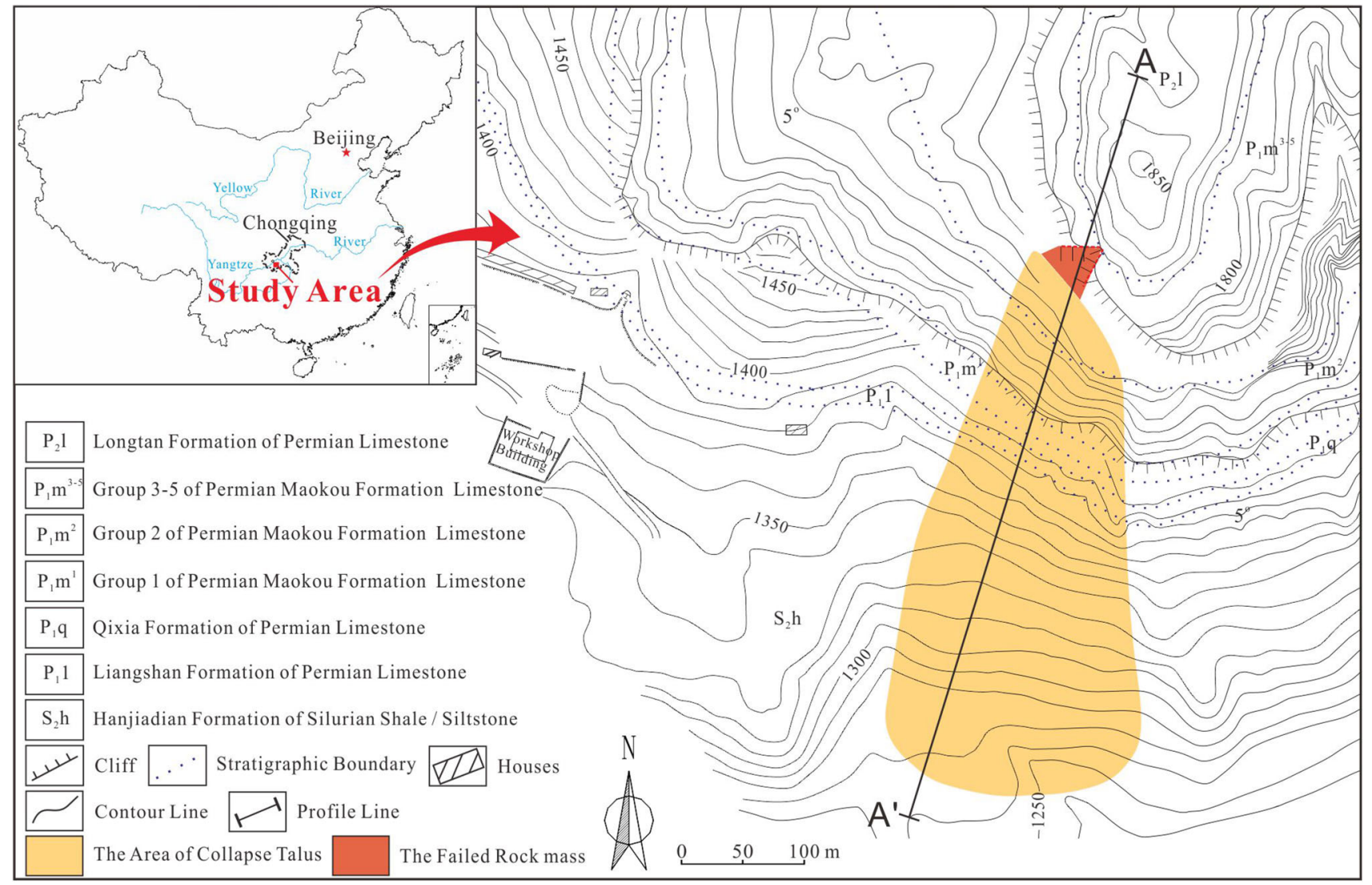

(a) Location of the Zengziyan rockfall

Figure 2. (a) Location and profile section of the failed Zengziyan cliff. The picture in the upper right corner of (b) taken after the failure shows the unloading fissures on the back scarp. 


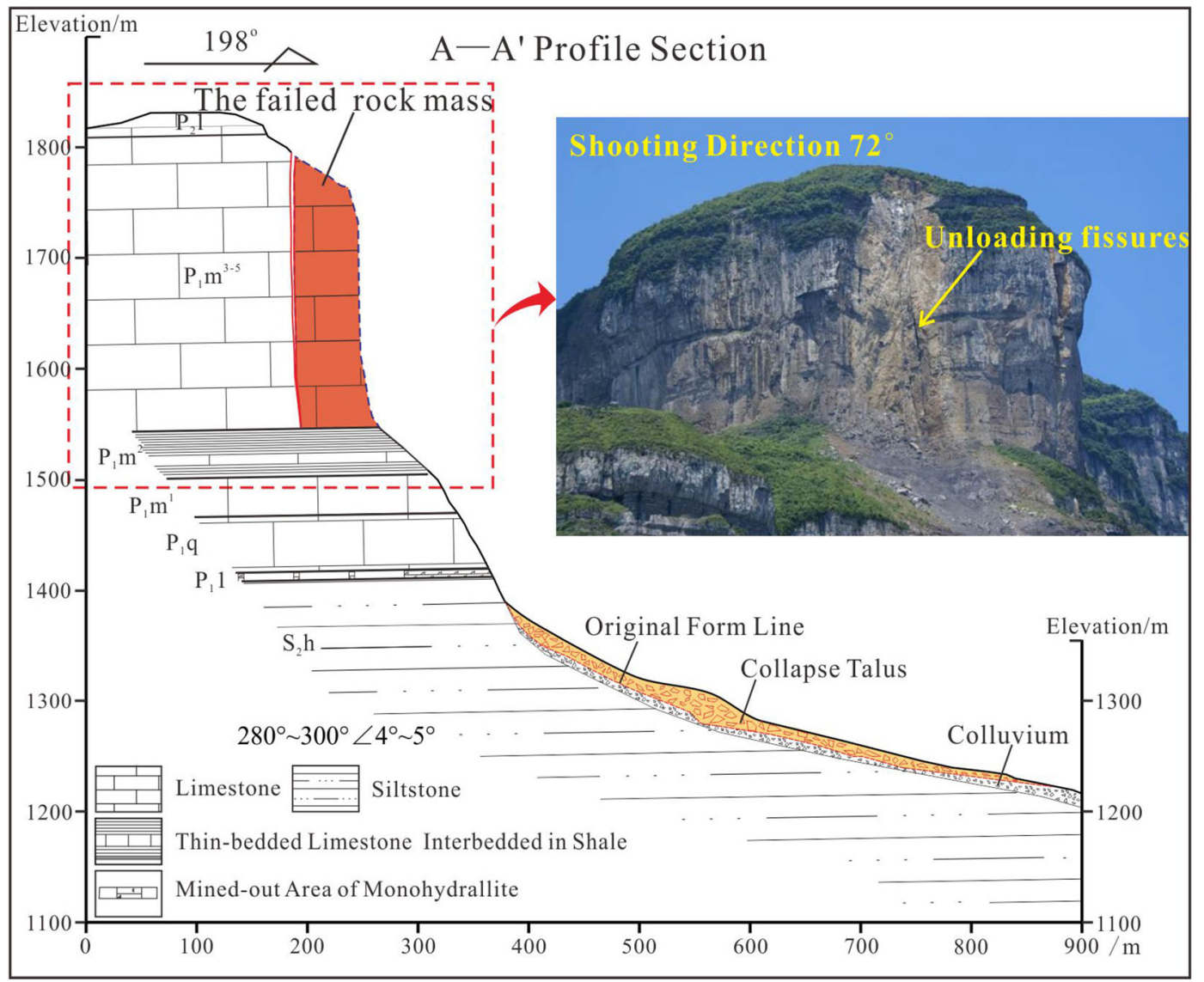

(b) A-A' profile section

Figure 2. continued

penetrate deep enough to make such rock mass independent from cliffs relatively.

(3) The rock mass has a large height-diameter ratio. Its own gravity load compresses the bottom of the rock mass. In addition, the rock mass is significantly affected by exogenous action factors. Under the long-term effect, the bottom zone deteriorates into damage and exhibits broken shapes.

(4) Hydrodynamism, differential weathering, karstification, mining activities and other exogenous action exert a significant influence, and an unstable rock mass shows different amounts of strength in different parts of the rock mass.

\subsection{Evolution of the disaster process of unstable rock masses at cliffs}

\subsubsection{Characteristics of the evolution stage of cliffs}

From the viewpoint of geomorphic evolution, rockfall and other geological disasters are a type of geo- morphic process affected by gravitational forces, hydrological processes or human activities (Keiler and Fuchs 2016). The formation of the unstable rock mass at Zengziyan cliff also started from geomorphic evolution. The region is in the eastern limb near the axis of the Jinfo Mountain syncline, which is the secondary tectonic unit of the Jinfo Mountain quaquaversal bundle of the fold. The upper hard and lower soft strata are a feature of this region, resulting from different sedimentary environments. The vertical uplift and river incision that had taken place since the new tectonic movement began in the region has produced steep upper and gentle lower slope geomorphological features of the Zengziyan cliff. Subsequent unloading caused a stress redistribution and stress differentiation at the edges of the cliff. Meanwhile, the stress differentiation was amplified by the compression of the soft layer underneath. This resulted in the strata near the top of the cliff producing a tension stress concentration zone, which first created ground fissures that then developed into unloading fissures downward and resulting in a structural relaxation of the cliff rock mass. 


\subsubsection{Time-dependent deformation stage of the rock mass}

The unloading fissures seen in figure 2 are the product of the time-dependent deformation of the cliff. Weathering profoundly affected the cliff, especially the rock in the free-space areas. The shale and argillaceous limestone at the lower part of cliff were disintegrated by weathering, which generated further deformation in the free-space direction under the overlying rock's gravity load. Erosion due to precipitation widened and deepened the ground fissures. This also made the karst fissures into pipelines in the carbonate rock strata, which continued to expand. With the development of this deformation, the compressive stress applied to the bottom zone of the rock mass increased, as well as increasing the number of fracturing fissures that developed upward. These fracturing fissures gradually connected with the unloading fissures to produce an unstable rock mass at the edge of the cliff.

\subsubsection{Failure stage of the unstable rock mass}

Because of precipitation and other external natural forces, the fissures inside the unstable rock mass developed further, while mining activity under the unstable rock mass intensified the deformation and deterioration. These circumstances significantly accelerated the failure process of the unstable rock mass. After the unstable rock mass collapsed, the broken rock blocks fell from the cliff and ran out along the slope under the cliff, transforming into a fragment flow. This is the typical disaster chain process of a rockfall to a long-runout fragment flow.

\section{Failure modes of unstable rock masses at cliffs}

Regardless of the underlying background geological conditions and exogenous action factors, the impact on stability and failure modes of an unstable rock mass can, eventually, be expressed through the aspects of both the morphological structure and the strength property of the rock mass. Due to its large height-diameter ratio, the bottom of an unstable rock mass is subject to a higher gravity load than the middle or the upper parts of the mass, so the strength is more likely to decrease at the bottom. Furthermore, there are apparent differences in the physical and mechanical properties between the lower and upper parts of high, steep unstable rock masses. Accordingly, the structural characteristics and the strength of the bottom zone play a key role in the overall stability and failure mode of an unstable rock mass. Based on this line of reasoning, we introduce three common failure modes of unstable rock masses at cliffs, and provide a detailed analysis focusing on the fracturing-crashing mode of rockfall.

\subsection{Base slide and toppling}

A review of previous data and studies shows that both base slide and toppling are common failure modes (Huang 2012). Unstable rock masses at cliffs prone to base sliding generally possess a layered soft base, where the sliding zone is formed in the soft base with a lower strength. When the soft base is subject to long-term loading, softening or disturbance through mining, a more pronounced deformation occurs and the unstable rock mass fails in a base slide. Typically, the head of the rock mass displays an inward rotation deformation due to sliding in this type of failure, so this failure mode is also referred to as an inward rotation failure. For instance, the Wangxia unstable rock mass in China, which is a group of steep dip fissures along the structural joints at the edges of a cliff, produced a slab-shaped unstable rock mass due to karstification and underground mining. Surveys show that the soft base was squeezed to become an extrusive deformation characteristic under the long-term gravity load of the overlying hard rock, which has resulted in a differential settlement of this slabshaped rock mass, as well as shear and rotation along the soft layers that have led to slide failure (figure 3).

If an unstable rock mass at a cliff exhibits morphological top-heavy characteristics, and is subject to a disturbance from underground mining or erosion, then the toe of the rock mass can become a cavity that decreases the toe's load-bearing capacity. In this case, the mass centre of the rock tends to move outward, with the toe of the unstable rock mass acting as the moment rotation point. As the deformation develops, the overturning moment gradually increases and eventually exceeds the anti-overturning moment, at which point toppling could occur. This can also be referred to as an outward-rotation failure, i.e., the head of the failed rock mass rotates outward from the cliff. An example of this failure mode can be seen on the Sella cliff, Italy, where sections that have toppled or are prone to toppling can be clearly observed from the 

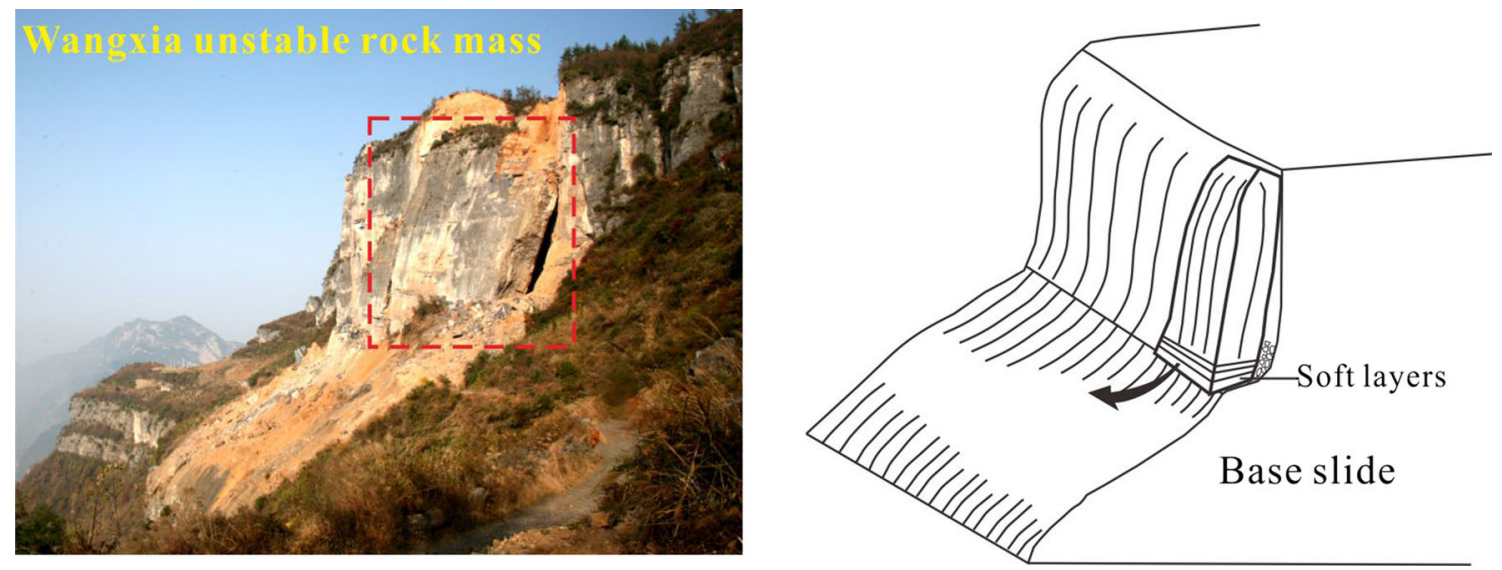

Figure 3. Base slide of the Wangxia unstable rock mass at the cliff. The base slide failure mode of the Wangxia slab-shaped rock mass was induced by karstification, underground mining and underlying soft layers.

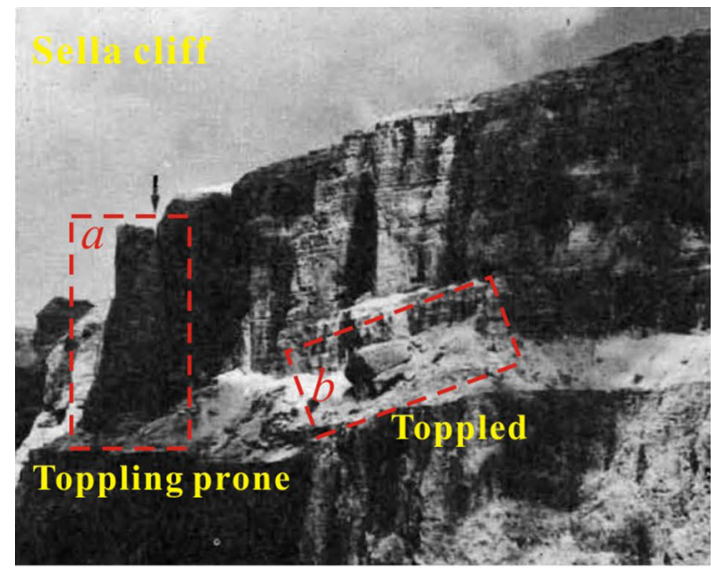

(a)

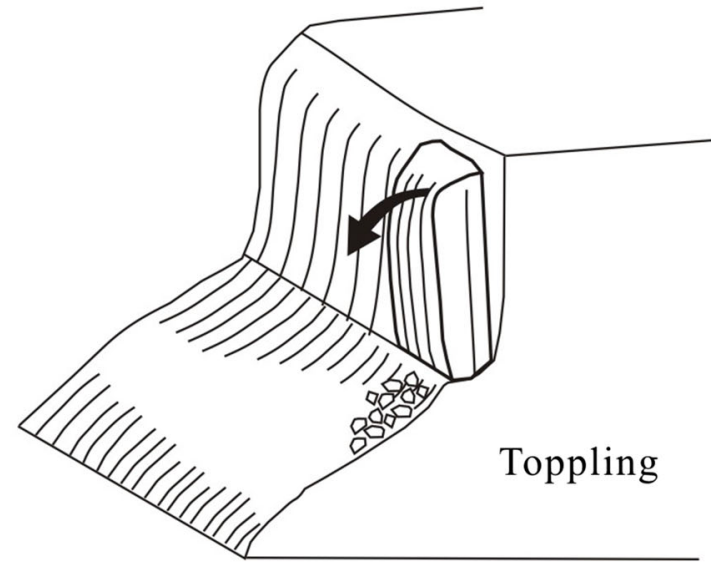

(b)

Figure 4. Toppling failure for an unstable rock mass at the cliff (the photo is adapted from Poisel and Eppensteiner 1988). The rock mass in the left red dotted box (a) is in danger of toppling, while the cliff section in the right red dotted box (b) has already toppled.

free-space side of the thick-bedded dolomite cliff (Poisel and Eppensteiner 1988) (figure 4).

\subsection{Fracturing-crashing mode of rockfall}

A thorough investigation into the failure process of the unstable rock mass at Zengziyan cliff revealed essential differences from other common failure modes of unstable rock masses at the cliff. The observed failure mode can be divided into four stages for detailed analysis (figure 5).

\subsubsection{Damage development}

Rock is a material that typically tends to possess some initial damage. As mentioned above, unstable rock masses at cliffs are subject to multiple influential factors. When these factors occur in the bottom zone of the rock mass under the gravity load of the overlying rock, it exacerbates the development of rock damage and induces deterioration in the rock's mechanical properties. Note that the differences between the bottom zone and the upper zone of an unstable rock mass only occur gradually.

During this stage, more fine fissures emerge in the bottom zone. These fine fissures represent small deformations in macro-performance through their cumulative effect. This is a long-term process, which can be referred to as the damage development stage. We found the unstable rock mass at Zengziyan cliff to be mostly in this stage before collapse.

\subsubsection{Compression-induced fracturing}

As the development of damage, the fine fissures expand increasingly and extend to macro fissures, i.e., the compression at the bottom zone results in 

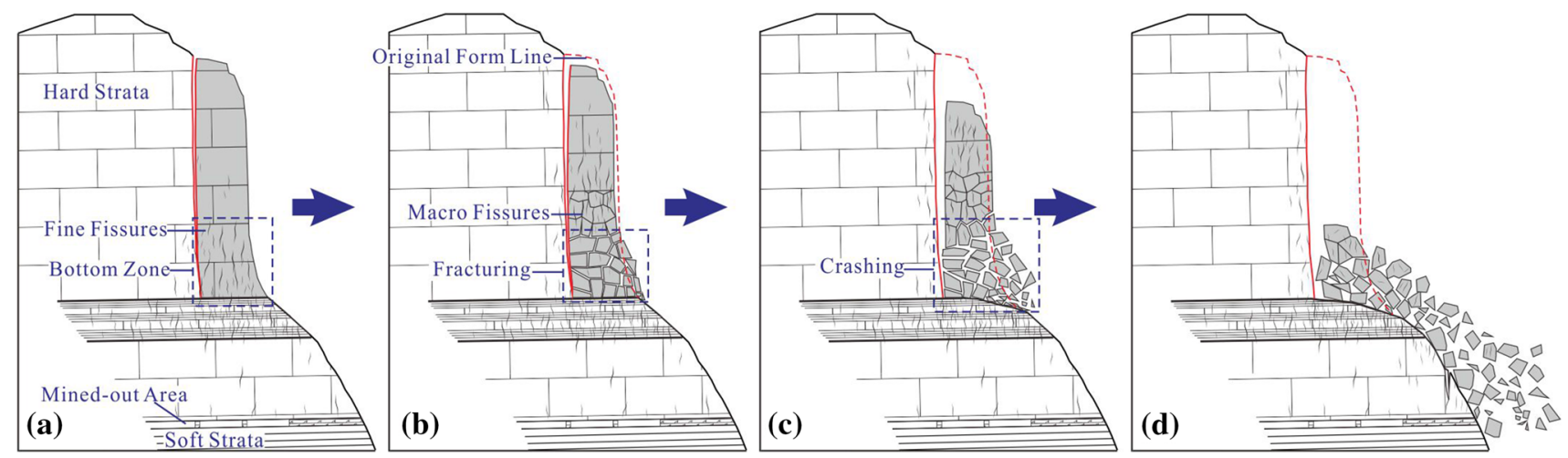

Figure 5. Fracturing-crashing mode of rockfall of an unstable rock mass at the cliff: (a) damage development stage, in which fine fissures converge in the bottom zone; (b) compression-induced fracturing stage; (c) crashing stage, in which cracking and damage of the rock mass rapidly develop from low to high, the middle and upper rock mass is crashing down and (d) the stage of overall rockfall that ends the initial failure process.

a crack in the rock. At this point, the unstable rock mass enters the compression-induced fracturing stage, which also be called the damage-accelerating development stage. This stage is much shorter than the previous stage. In general, the deformation process described prior to the collapse of an unstable rock mass begins at this stage. The sharp increase of deformation of the unstable rock mass is the most prominent characteristic of this stage.

\subsubsection{Rock mass crashing}

After the formation of macro fissures, the rock at the bottom zone undergoes disintegration induced by compressive fracturing, losing the capacity to bear the overlying rock. The overlying rock mass crashes down subsequently and cracks into smaller blocks. The broken rocks inevitably became rubble and bump into each other. The damage to the middle and upper rock is accelerated significantly through this process. Thus, this stage is also referred to as the cracking and damage growth stage.

\subsubsection{Overall rockfall}

Eventually, the unstable rock mass undergoes crash and disintegration during the initial failure process. From the viewpoint of energy, most of the potential energy of the unstable rock mass converts into kinetic energy, represented by the falling away of the rocks and the high-speed motion of the broken fragment, without considering the consumed internal energy during this failure process. The remainder of the potential energy is likely to be converted into strain energy at the same time. This

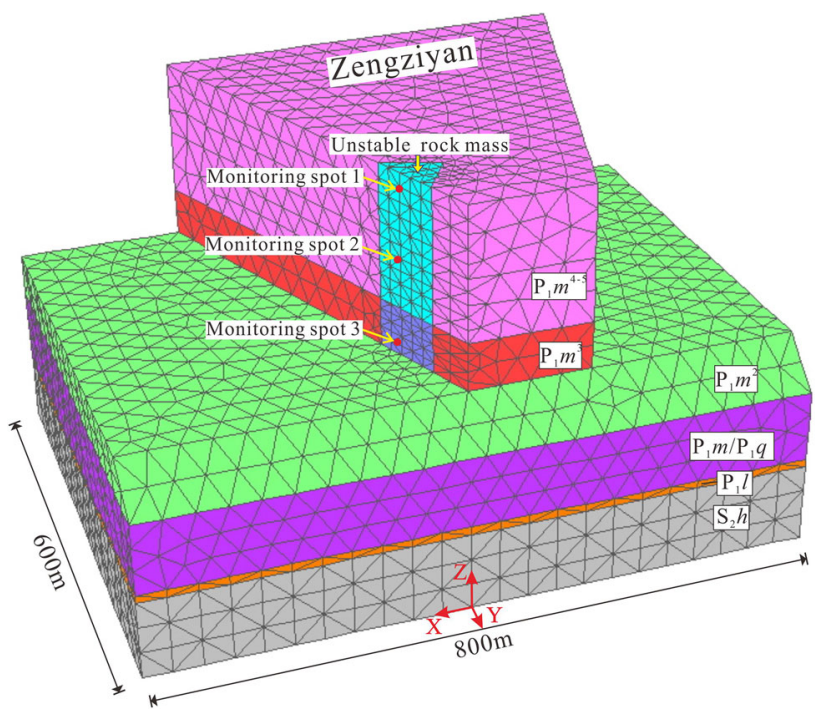

Figure 6. Three-dimensional numerical model of the unstable rock mass at Zengziyan cliff. Six groups of strata were created to simulate the Zengziyan cliff. The length, width and coordinates of the model are shown in the figure.

part of the energy results in the cracking, deformation and disintegration of the unstable rock mass during falling and crashing.

\section{Numerical analysis of the fracturing-crashing rockfall of the unstable rock mass at Zengziyan cliff}

\subsection{Establishment of model and selection of parameters}

Using local geological environmental conditions, a generalised numerical analysis model of the unstable rock mass at Zengziyan cliff was created using the FLAC ${ }^{3 \mathrm{D}}$ program. The model, shown in 
figure 6 , has a maximum height of $480 \mathrm{~m}$ divided into 27,234 elements and 5783 nodes. In addition, three monitoring spots were set at the top, middle and bottom of the free-space side of the rock mass.

Table 1 provides the physical and mechanical parameters used for the numerical model. The parameters were determined using a combination of geological engineering analogies and empirical experiments.

\subsection{Simulation conditions}

Using the discussion provided in the previous section, our analysis of the rockfall of the unstable rock mass at Zengziyan cliff indicated that the rock mass failed as a result of mechanical property deterioration in its bottom zone, followed by fracturing and crashing. Based on this analysis, the effect on the failure mode of the damage and deterioration in the bottom zone of the unstable rock mass was thoroughly studied. We used our proposed model to simulate the damage and deterioration process of the bottom rock mass through strength reduction to validate the fracturing-crashing mode of rockfall.

Simulations were conducted using three different sets of physical and mechanical conditions for the unstable rock mass. The first set of conditions simulated the stability and deformation of the rock mass before the strength of the bottom zone deteriorated, while the second set of conditions gradually lowered the equivalent strength of the bottom zone through adjustment of the relevant parameters. The physical and mechanical parameters of the bottom zone were examined using the median value of the first and third set of conditions to represent the transition property. The third set of conditions simulated the deformation and failure of the unstable rock mass corresponding to the fact that the bottom zone strength was consistent with the original strength of the failed rock mass at Zengziyan cliff. Each condition was set based on the prior value to simulate the weakening process in the bottom zone of the unstable rock mass.

\subsection{Numerical simulation results and analysis}

\subsubsection{First simulation}

The key to determining whether an unstable rock mass at cliff will undergo a fracturing-crashing rockfall is the analysis of the mechanical properties

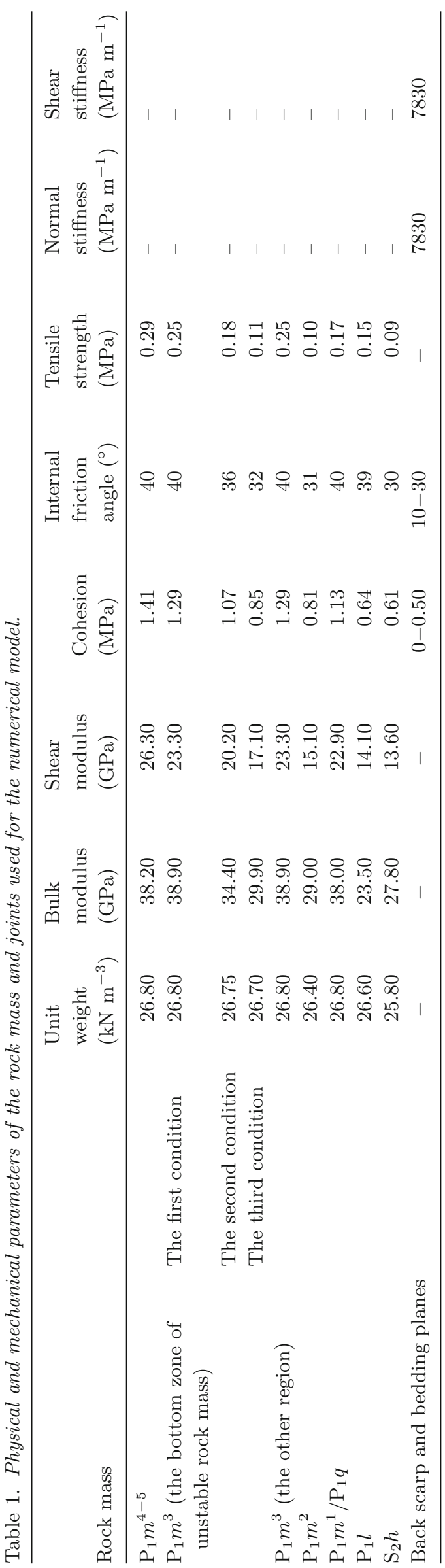




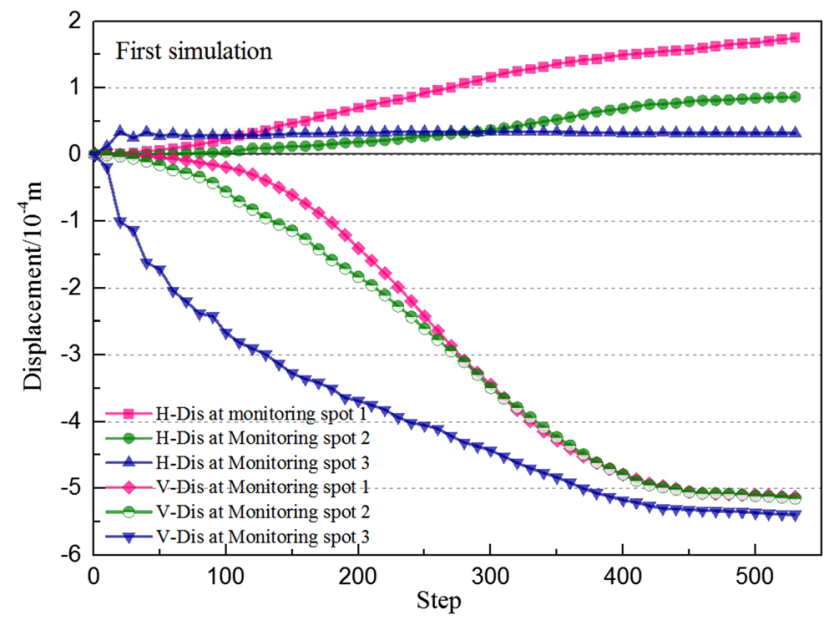

Figure 7. Curve of displacement versus step under the first simulation. Note that horizontal displacement is abbreviated to $\mathrm{H}$-Dis, and vertical displacement is abbreviated to $\mathrm{V}$-Dis in this figure and in figure 9.

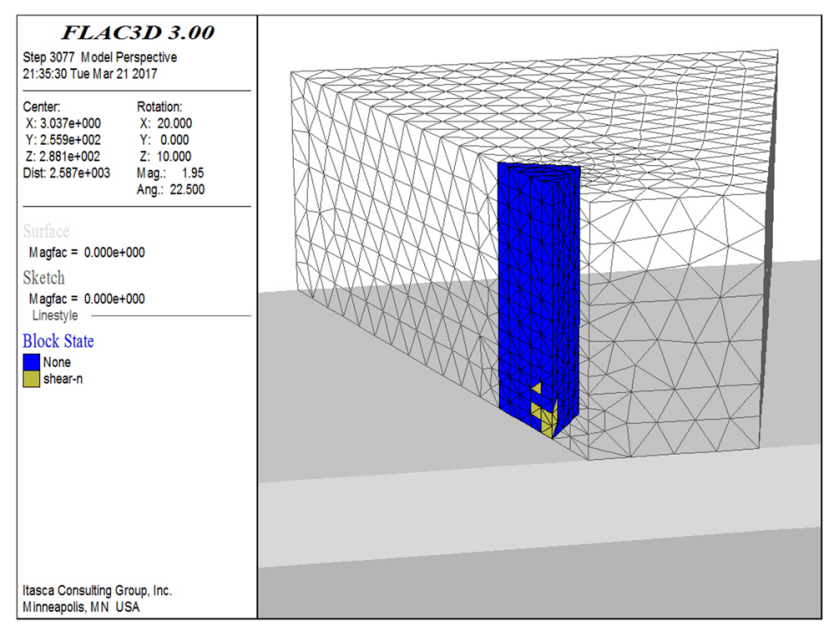

Figure 8. Plastic zone of the rock mass at Zengziyan cliff model under the first simulation. Only a few elements in the bottom zone close to the free-space side are in a shear plastic state.

of the bottom of the rock mass. The first simulation treated the rock mass at Zengziyan cliff as a rigid whole mass without considering any differences in mechanical properties between the bottom zone and the upper zone of the rock mass. This method is equivalent to conventional unstable rock mass models (Hoek and Bray 1977). Due to the higher strength at the bottom compared with the other simulations, the model converged after only 536 calculation steps after initial equilibrium. Data from the three monitoring spots show that the maximum horizontal displacement appears at the head of the high, steep rock mass due to the amplification effect on elevation (figure 7). After deformation compatibility, the model displays a quicker increase in horizontal displacement in the middle and upper zones of the rock mass compared to the bottom zone. Horizontal displacement at the bottom remains stable, exhibiting a slight drop after 260 steps. Note that the change in vertical displacement is different from that of the horizontal displacement. The vertical displacement of the bottom zone is about 3-5 times that of the vertical displacement in the middle and upper zones. After 375 steps, the vertical displacements of the middle and upper zones gradually increase to values similar to that of the bottom zone vertical displacement, and the increase in velocity slows down. The maximum displacement deformation order of magnitude of the high, steep rock mass under the first set of conditions was only $10^{-4} \mathrm{~m}$. Compared to the dimensions of the rock mass itself, the deformation was very tiny, and was not visible in the macro view of the entire rock mass. As shown in the distribution diagram of the plastic zone, only individual elements close to the free-space side of the bottom zone of the rock mass constituted a shear plastic zone (figure 8). All of these observations show that the rock mass at Zengziyan cliff remained in a stable state under the first set of simulation conditions.

\subsubsection{Second simulation}

The stress-concentrated area at the bottom of an unstable rock mass at the cliff is inevitably damaged by the long-term gravity load and many other factors, with the result that the strength of the bottom zone gradually decreases. Using the results from the first simulation, the second simulation reduced the equivalent strength of the bottom zone, with the model showing convergence equilibrium after 1182 computation steps. As the strength of the bottom zone decreases, the displacement deformation of the rock mass at Zengziyan cliff exhibits significant changes (figure 9). The horizontal displacement of the bottom rapidly increases, exceeding that of the middle and upper areas after 569 steps. The changes in horizontal deformation of the middle and upper portions of the rock mass are different as the number of computation steps increases. The horizontal deformation rate of the upper zone first increases and then decreases, while the deformation rate of the middle zone first decreases then increases, exceeding the deformation rate of the upper zone after 1070 steps. The changes in vertical displacement are more obvious. The vertical displacement of both the middle and 


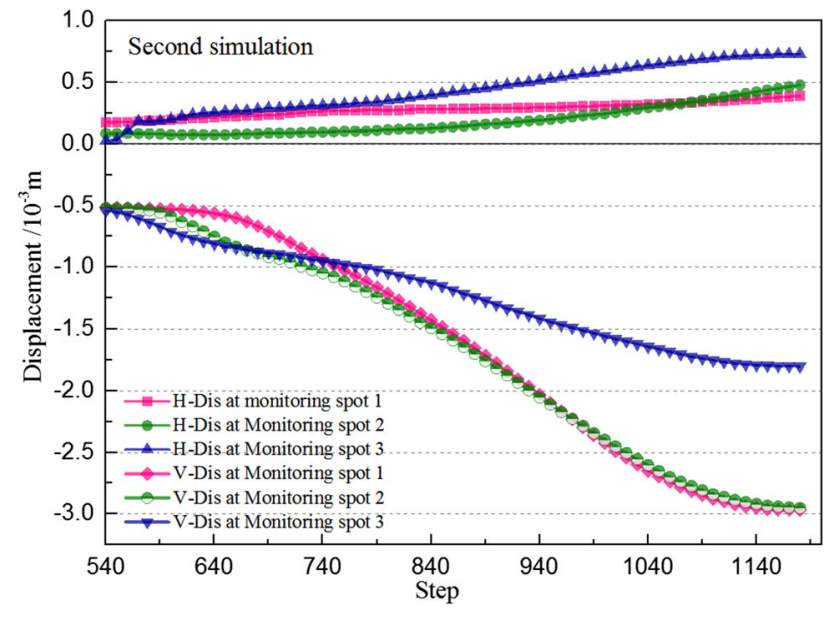

Figure 9. Displacement curve versus step under the second simulation. The H-Dis of spot 3 is higher than that of the other spots, but its V-Dis is the lowest when the simulation converges in the second simulation. This is the opposite of the result in the first simulation. This change is also a manifestation of the time-dependent difference in deformation.

upper zones surpasses the vertical displacement of the bottom zone after 750 steps, and this difference gradually increases as the computation steps continue. These observations illustrate an apparent time-dependent difference in deformation. The range of the plastic zone under the second set of simulation conditions also becomes significantly larger (figure 10). The shear plastic zone is concentrated at the bottom of the rock mass, which indicates that some local elements in this area failed in a compression-shear fashion. However, the plastic zones maintain a discrete distribution and do not connect into a continuum. In addition, the overall deformation of the rock mass is still small. Based on these observations, it was determined that the rock mass at Zengziyan cliff did not lose stability over the course of the simulation.

\subsubsection{Third simulation}

For the third simulation, the physical and mechanical parameters of the bottom rock zone were further reduced, with the corresponding model not converging after 5000 computation steps. The velocity-step curves for the full simulation in the previous two simulations show that the velocities corresponding to the various monitoring spots first increased and then decreased. This observation indicates that the model gradually stabilised as the number of iterations increased in these simulations. However, the velocity-step curve in the third simulation exhibits an approximately constant increasing rate, which indicates

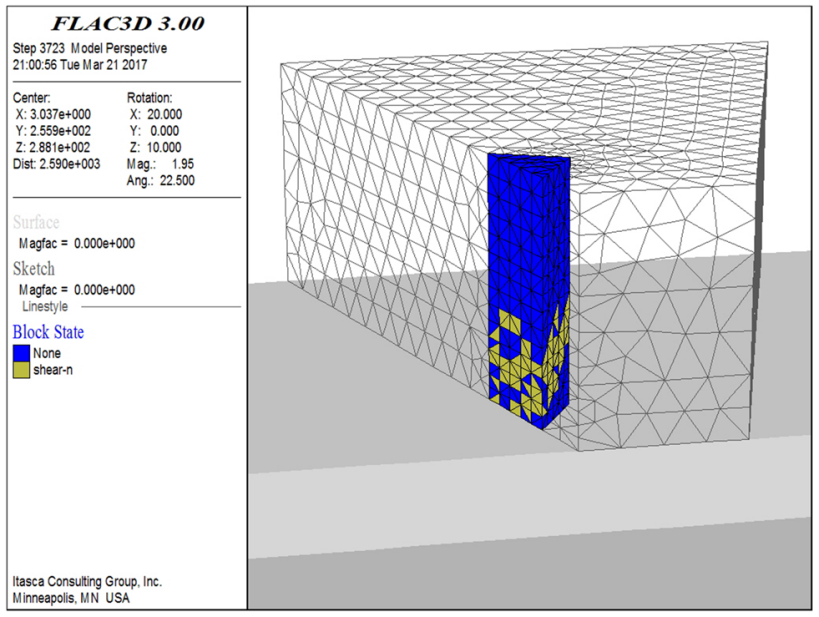

Figure 10. Plastic zone for the rock mass at Zengziyan cliff model under the second simulation. There are more elements in the shear plastic state in the bottom zone, but these elements do not connect into a continuum.

that the model was in a plastic flow state, i.e., the high, steep rock mass lost its stability and failed (figure 11).

The displacement vector of the rock mass under the third set of conditions shows that, with the further decrease in strength of the bottom zone, the deformation of the rock mass increases (figure 12). The bottom zone primarily shows a buckling and crashing deformation towards the free-space side. The middle and upper zones exhibit an apparently increasing drop tendency, likely due to the failure of the bottom zone. In the third simulation, the deformation of the unstable rock mass rapidly jumps to

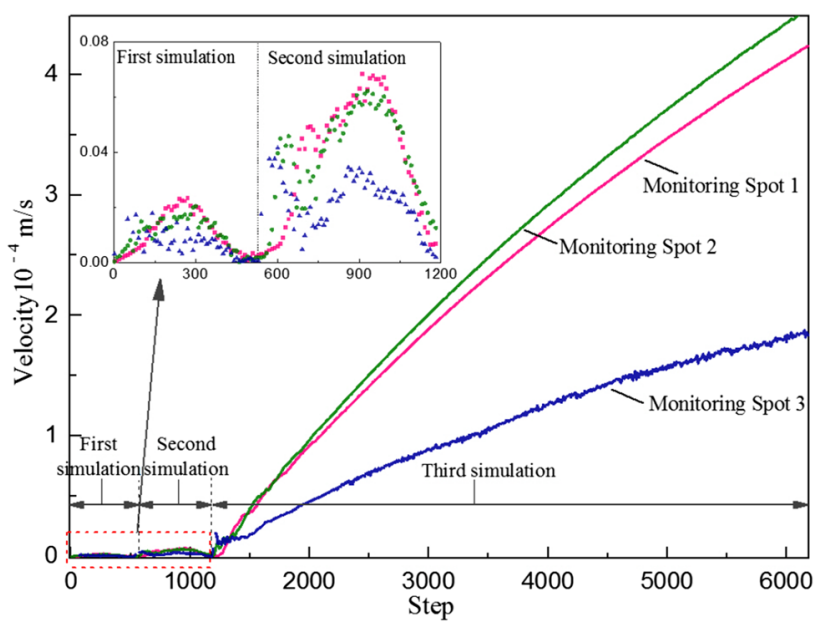

Figure 11. Velocity curve versus the step for the monitoring spots in the three simulations. A magnified graph showing the velocity curves for the first and second simulations is in the upper left corner, and curves of both sections show a similar trend. 


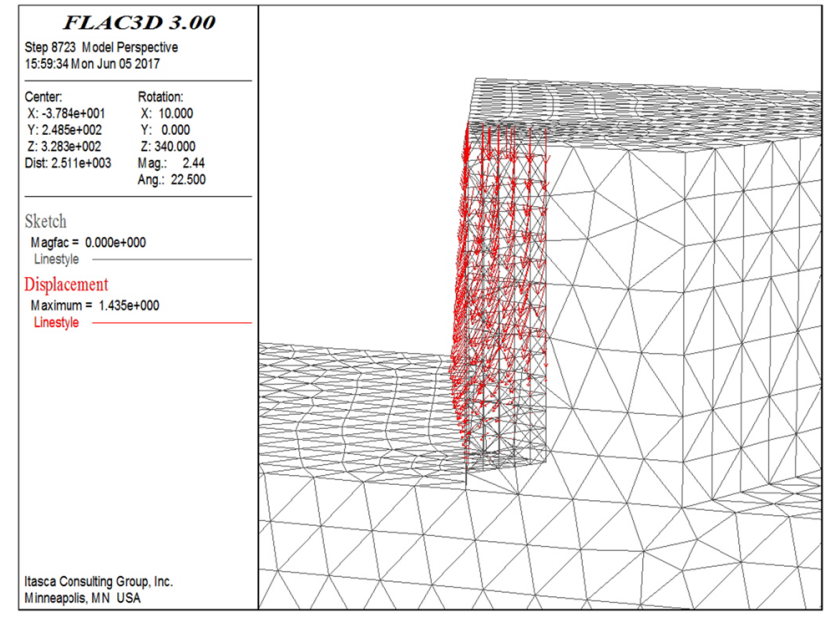

Figure 12. Displacement vector for the unstable rock mass at Zengziyan cliff under the third simulation. The displacement vector shows a deformation due to buckling and crashing failure at the bottom zone of the high, steep rock mass.

its maximum value of $1.435 \mathrm{~m}$, and the change in the plastic zone is more pronounced. As per the distribution diagram of the plastic zones (figure 13), we can readily see that the plastic deformation zone at the bottom is mostly controlled by a compressive shear failure, while the middle zone exhibits both a shear and a tension failure and the upper zone is controlled by tension failure. This result indicates that the middle and upper rock masses were inevitably subject to a tension disturbance due to the failure at the bottom, which subsequently fractured and disintegrated during tension and drop. The unstable rock mass at Zengziyan cliff overall exhibited a fracturing-crashing failure characteristic consistent with the observed rockfall.

\subsubsection{Factor of safety and stability}

From the calculated factor of safety (FOS) of the simulated unstable rock mass at Zengziyan cliff (figure 14), we can see that the linear change of the FOS is completely consistent with the decreasing regularity of the equivalent strength at the bottom of the rock mass. This observation again reflects the effect on the overall stability of the rock strength at the bottom of the rock mass. The FOS under the first simulation is 1.35 , and the rock mass maintained an overall stable state. The FOS under the second simulation decreases to 1.13. As the overall deformation increased and some local areas failed, but the rock mass at the bottom continued to support the middle and upper portions

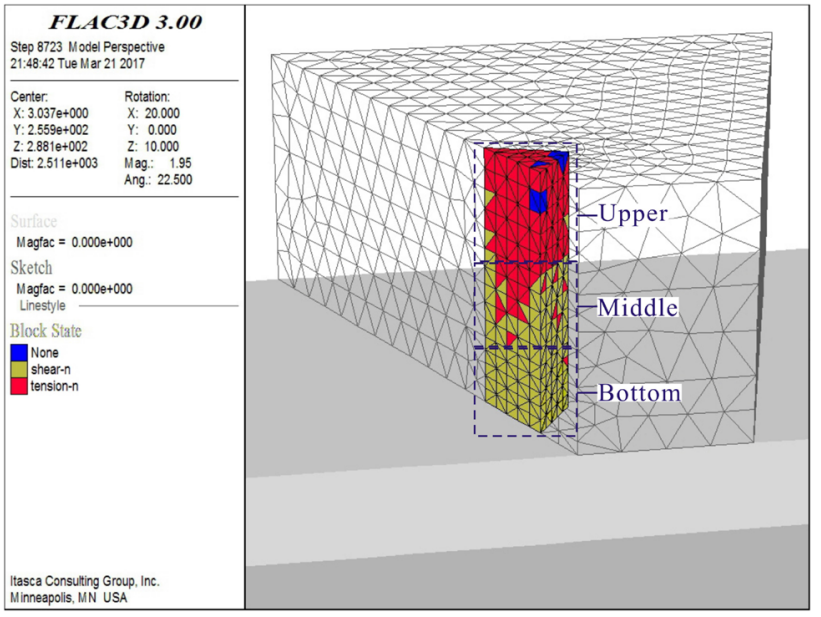

Figure 13. Plastic zone for the unstable rock mass at Zengziyan cliff model under the third simulation. The bottom is primarily a shear plastic zone, the middle is a transition zone and a tension plastic zone dominates the upper part of the rock mass.

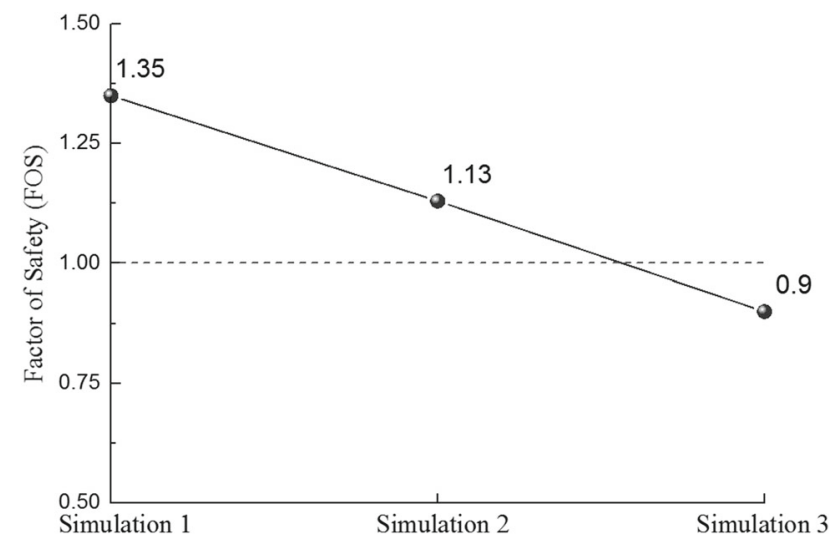

Figure 14. Safety factor of the rock mass at Zengziyan cliff under the three simulations. The linear change in FOS is completely consistent with the decreasing regularity of equivalent strength at the bottom of the rock mass.

of the rock mass. The rock mass did not lose overall stability, but was no longer completely stable. With the continuous decrease in rock strength in the bottom zone, the FOS under the third simulation decreases to 0.90 . That is, the bottom zone failed completely and the overall deformation of the rock mass intensified. This meant that the rock mass exhibited an unstable state. By considering the distribution of the plastic zone, we can identify the rock mass at Zengziyan cliff as unstable and prone to fail.

\section{Discussion}

In the case of the rockfall of the Zengziyan cliff, it was not difficult to find a significant difference 
in rock mass strength and failure mode between the fracturing-crashing rockfall that occurred and other common failure modes. First, as far as the rock strength is concerned, there were apparent differences in mechanical properties between the upper and bottom zones of the failed rock mass itself due to the long-term effects of gravity load, deformation of the soft base zone and disturbance from mining activities. The vertical fissures in the bottom zone were more developed, and more prone to buckling and crashing under the existing compressive stress environment. Second, as far as the failure modes were concerned, the fracturing-crashing rockfall started with a fracturing failure of the bottom zone, followed by the middle and upper zones falling away due to the loss of support. The overall collapse under these conditions occurred from the lower part of the rock mass to the higher part, which is different from the other common rockfall modes.

The failed rock mass also had a high kinetic energy, which could not only lead directly to severe casualties and economic losses, but also readily transform into a long-runout fragment flow. Thus, this type of failure ends up forming a disaster chain that can pose a huge safety hazard to local towns in mountainous areas, transportation infrastructure and hydraulic engineering projects. With the accelerated development of ecological and economic construction in the mountainous areas of southwestern China, the disaster potential of unstable rock masses at cliffs has drawn increasingly wide attention.

To avoid making our analysis overly complicated, this paper did not consider hydraulics or other external factors in the numerical simulations. However, a priority for further research should be to conduct a mechanical analysis in more complex environments so as to establish stability evaluation methods for unstable rock masses at cliffs prone to fracturing-crashing rockfall and developing preventative measures against potential fracturingcrashing rockfall. This research would also benefit prevention and mitigation from geological disasters. We think that the practical usefulness of this study is mainly reflected in two aspects. One is the early detection of an unstable rock mass. The accuracy rate of recognition will improve when we know the failure mechanism of such rockfall. The other is targeted control which can be accomplished around the deteriorated zone at the bottom of the same type of rock mass. It will be quicker and cheaper than the holistic control. Targeted control will play a greater role in the emergency management of geological disaster.

\section{Conclusion}

Focusing on the commonly found large unstable rock masses at cliffs in the karst mountain areas of southwestern China, the rockfall at the Zengziyan cliff in Chongqing is taken as an example to disclose the development characteristics of unstable rock masses at cliffs prone to fracturing-crashing rockfall. The main findings of this study are concluded below:

(1) Characteristics for identifying are summarised, including the edge of a bootshaped slope, developed joints and fissures, large height-diameter ratio and different amounts of strength in different parts. All of the above features can be used in the early detection of the fracturing-crashing rockfall.

(2) A fracturing-crashing rockfall failure mode is proposed. Fine fissures, gravity load and external dynamic disturbance factors result in the damage evolution that eventually produces macro fissures. Compressive fracturing causes crashing in the bottom zone of the unstable rock mass, at which point the middle and upper parts of the unstable rock mass promptly fall away and break due to a loss of stability. In the final stage, the unstable rock mass collapses. This is the initial failure process of the fracturing-crashing mode of rockfall.

(3) With the help of numerical simulation, we confirmed that the deterioration in the strength of the bottom zone of the unstable rock mass at a cliff could directly result in a fracturingcrashing rockfall.

These results provide a new analytical model for evaluating similar rockfall disasters and provide important reference data for future mechanical analysis, stability evaluations and engineering prevention of unstable rock masses prone to fracturing-crashing rockfall.

\section{Acknowledgements}

This study was conducted with the financial support from the National Natural Science Foundation of China (No. 41702342) and National 
Key R\&D Program of China (2018YFC1504806, 2018YFC1504805).

\section{References}

Feng Z, Li B, Cai Q and Cao J 2016 Initiation mechanism of the Jiweishan landslide in Chongqing, south-western China; Environ. Eng. Geosci. 22 34-351.

Frayssines M and Hantz D 2006 Failure mechanisms and triggering factors in calcareous cliffs of the subalpine ranges (French Alps); Eng. Geol. 86 256-270.

Glastonbury J and Fell R 2008 A decision analysis framework for the assessment of likely post-failure velocity of translational and compound natural rock slope landslides; Can. Geotech. J. 45 329-350.

He K, Chen C and Li B 2018 Case study of a rockfall in Chongqing, China: Movement characteristics of the initial failure process of a tower-shaped rock mass; Bull. Eng. Geol. Environ., https://doi.org/10.1007/ s10064-018-1364-9.

Hoek E and Bray J 1977 Rock slope engineering (2nd edn); Institution of Mining \& Metallurgy, London.

Huang B, Yin Y, Liu G, Wang S, Chen X and Huo Z 2012 Analysis of waves generated by Gongjiafang landslide in Wu Gorge, three Gorges reservoir, on November 23, 2008; Landslides 9 395-405.

Huang R 2012 Mechanisms of large-scale landslides in China; Bull. Eng. Geol. Environ. 71 161-170.

Hungr O 1981 Dynamics of rock avalanches and other types of slope movements; PhD Thesis, University of Alberta, Edmonton, 500p.

Hungr O and Evans S G 2004 The occurrence and classification of massive rock slope failure; Felsbau 22 16-23.

Hungr O, Evans S G, Bovis M and Hutchinson J N 2001 Review of the classification of landslides of the flow type; Environ. Eng. Geosci. VII 221-238.

Corresponding editor: ARKOPROvo BISWAS
Hungr O, Leroueil S and Picarelli L 2014 The varnes classification of landslide types, an update; Landslides $\mathbf{1 1}$ 167-194.

Jones D B, Siddle H J, Reddish D J and Whittaker B N 1992 Landslide and undermining: Slope stability interaction with mining; In: Proceedings of the 7th International Society of Rock Mechanics congress, Aachen, pp. 893-898.

Keiler M and Fuchs S 2016 Vulnerability and exposure to geomorphic hazards: Some insights from the European Alps, Geomorphology and Society; Springer, Tokyo.

Li B, Feng Z, Wang G and Wang W 2016 Processes and behaviors of block topple avalanches resulting from carbonate slope failures due to underground mining; Environ. Earth Sci. 75 694-720.

Peisser C D, Helmstetter A, Grasso J R, Hantz D, Desvarreux P, Jeannin M and Giraud A 2002 Probabilistic approach to rock fall hazard assessment: Potential of historical data analysis; Nat. Hazards Earth Syst. 2 15-26.

Poisel R and Eppensteiner W 1988 A contribution to the systematics of rock mass movements; In: 5th international symposium on landslides, Lausanne, pp. 1353-1357.

Poisel R, Steger W and and Zeitler A 1991 Stability investigations of competent rock masses lying on an incompetent base; In: 7th ISRM Congress, International Society for Rock Mechanics, pp. 939-944.

Poisel R, Martin B, Rudolf H and Pavel L 2005 Geomechanics of hazardous landslides; J. Mt. Sci. 2 211-217.

Susan L N, Hungr O and Evans S G 2002 Large-scale brittle and ductile toppling of rock slopes; Can. Geotech. J. 39 773-788.

Terzaghi K 1950 Mechanism of landslides; The Geological Society of America, America, pp. 83-123.

Yin Y, Huang B, Liu G and Wang S 2015 Potential risk analysis on a Jianchuandong dangerous rockmass-generated impulse wave in the Three Gorges Reservoir, China; Environ. Earth Sci. 74 2595-2607.

Yin Y, Sun P, Zhang M and Li B 2011 Mechanism on apparent dip sliding of oblique inclined bedding rockslide at Jiweishan, Chongqing, China; Landslides 8 49-65. 